\title{
Metaphor, Verstehen or Neither: A Reflection on Hypnotic Analgesia and Active Ingredients in Psychotherapy
}

\author{
ROBERT A. KARLIN ${ }^{\text {a,b }}$ \\ ${ }^{\mathrm{a}}$ Rutgers University-New Brunswick \\ ${ }^{\mathrm{b}}$ Correspondence concerning this article should be addressed to Robert A. Karlin, Ph.D., SAS - Psychology, Tillett \\ Hall, 53 Avenue E, Piscataway, NJ 08854 \\ Email: rakarlin@psych.rutgers.edu
}

\begin{abstract}
Hamburg, an experienced and expert therapist, presents two successful psychotherapy cases. In both cases he viewed success as being the product of his use of metaphor, the patients' successful surmounting of a high difficulty task, hypnosis, and nonspecific factors. One of the cases involves a medically unexplained chronic and disabling pain. With a couple of brief vignettes of my own, I suggest careful screening, as using hypnosis to control medically unexplained, chronic pain may cause problems for some patients with major psychopathology (e.g., paranoid schizophrenia). Next, I note that clinical data will reflect back to us the a priori assumptions and interests we bring to it. As an example of how often and misleadingly this can happen, I discuss the autobiographical nature of clinical personality theories. Finally, I agree with Hamburg about the importance of ubiquitous nonspecific effects and note my difficulty accepting that they may be more important than the specific things we do deliberately in psychotherapy.
\end{abstract}

Key words: hypnosis; eclectic therapy; cognitive behavior therapy; metaphor; pain management; chronic pain; depression; homework; nonspecific effects; clinical case studies; case studies

One of the many, well-known aspects of Milton Erickson's hypnotic inductions was the use of metaphorical phrases. By using nonlinear statements without obvious connection to hypnosis, the hypnotist brings the patient into a receptive state of mind with some emergence of primary process thinking coming to the fore. In that state, the unconscious, seen as powerful and usually benign, can be asked to heal the patient of a variety of physical and psychological ills. (Note that casual reification of concepts, such as the unconscious, is often seen in discussions of Ericksonian hypnosis.)

Hamburg (2018) extends the notion of metaphor to specific tasks used in psychotherapy. In the first case, he is working with Margie, a somewhat skeptical, working class patient who 
will not give her trust to a helping professional without evidence of his good intentions. Margie, who is badly in debt due to impulse buying, seems quite depressed and is in the midst of a very narrow, unsatisfactory life. At one point in this case, Hamburg sits on the floor beside his patient and helps her with a jigsaw puzzle. The experience seemingly persuades Margie that tasks she thought impossible can be addressed and successfully completed.

The second patient is Amy, a successful young woman who is highly hypnotizable. Extensive physical workups had failed to find a medical explanation for Amy's chronic pain. Hamburg works with her hypnotically despite the accepted rule of thumb that hypnosis does not work for psychogenic pain. Hamburg uses hypnotic pain control instructions similar to those employed by the well-known hypnotherapist Joseph Barber (1996), with a task involving complex movement to the beats of a metronome to provide pain relief. In Amy's case, treatment helps the highly hypnotizable patient eventually control, diminish, and largely rid herself of chronic disabling pain. Hamburg attributes his success in both cases to sitting next to each patient (once with Margie on the floor with a jig-saw puzzle and once with Amy in front of a computer screen) and his use of metaphorical tasks at which each patient learns to succeed.

I admire Hamburg's work in both cases. He exemplifies the experienced, hard-working, thoughtful, well trained, eclectic, and talented psychotherapist. His hypnotic induction, detailed in an Appendix to the paper, is lovely. I have already used a version of it clinically. I see his sitting next to Margie and Amy as an expression of who he is as a person and as a therapist. In each case he is a caring, thoughtful, gentle doctor who is willing to become, for an important moment, a peer and a friend.

When I read Hamburg's description of what happened, I saw what happened as illustrating the power of verstehen. Verstehen is a form of understanding that allows the therapist to access several points of view, including the patient's (Woolfolk, 2015). Hamburg's ability to state Margie's thoughts as she attempted the puzzle was important to her, along with his caring manner and gentle voice.

It is unsurprising that verstehen came to my mind, as I had recently been thinking about it. We come to clinical data with a concept in mind and the data seem to reflect the concept back to us, as it has done with so many clinicians in the past. What we see is important to us and our thinking about what we do. But it can be quite misleading. Teaching a graduate seminar or a workshop, I might well have put forth my explanation and occupied students with learning about the importance of verstehen, creating yet another goal for them to achieve.

As for metaphor, my sense is much less strong than Hamburg's about its utility as compared to other forms of symbolism, imagery, and the like. In fact, I'm not sure that his thinking in terms of metaphor makes much difference. Nor is he. Although he views metaphor as central, he is well aware that a large number of factors, along with ubiquitous nonspecific effects, may have contributed to the causal nexus. Hamburg's hypothetical workshop might have emphasized mastering the uses of metaphor (as opposed to mine about verstehen). This seemingly innocuous habit of using plausible explanations to explain good therapy outcomes may have more nefarious effects than are obvious. I will discuss this problem and its 
implications at some length below. But first I want to discuss Hamburg's second patient, Amy, the young woman with medically unexplained chronic pain.

\section{AMY AND HYPNOSIS}

As Hamburg says, the traditional view is that hypnosis doesn't work for psychogenic pain. However, as he shows and I have found in my clinical practice, there are differences in psychogenic pains and some can respond, within limits, to hypnotic suggestions. If fact, I have one such case in treatment now. There are also some reports that mindfulness approaches to chronic psychogenic pain can be useful (e.g., Gardner-Nix, 2013; Kabat-Zinn, 2013).

My experiences with such cases goes back to the mid-1970s. Those experiences occasioned some warnings previously expressed only at professional workshops (Karlin, 2005). Early in my use of hypnosis I had two cases, one involving a middle-aged woman who today would be diagnosed with borderline personality disorder, and the other involving a young woman who had experienced several psychotic episodes resulting in psychiatric hospitalizations.

The tenor of those times in behavior therapy circles was strongly oriented toward getting rid of symptoms. Fears about substituted symptoms were being ignored by those of us who were happily escaping the caveats of traditional psychoanalysts. In fact, we were seeing patients freed of their phobias and other problems and then showing increased functioning, self-discipline, and self-esteem in other areas of their lives (Lazarus, 1971).

Hypnosis had been the first victim of Freud's symptom substitution hypothesis (Ellenberger, 1970). If curing phobias with exposure techniques had only beneficial effects, why not also rid patients of psychogenic pain? The borderline patient had been referred to me with a history of over a dozen joint surgeries. She hobbled into my office. After initial discussions, which to my youthful ears told me nothing in particular, I hypnotized her and suggested that the pain diminish and go away. She left my office pain free. When she came back the next week, she once again hobbled into my office. I asked what had happened. She replied that with her new freedom from pain, she had decided to do some mountain climbing over the weekend. She had happily climbed halfway up the mountain and then found she could not move at all. She was stuck there and had to be carried down. I modified my hypnotic instructions and worked with her, reasonably successfully, on the myriad other problems in her life.

While there were elements of humor in this first case, there were none in the second. A young woman reported feeling pain throughout her body. If an area of her body was not hurting at the moment, it soon would be. Initial discussions revealed that she was fairly well functioning at the moment and was happily involved in an ongoing lesbian relationship. However, as noted above, she had been hospitalized in the past during what sounded like paranoid psychotic episodes. Despite that clear warning sign, I hypnotized her and suggested that she become pain free. The following week she had difficulty getting to my office, finally coming in a few days later than planned. By that time, she was overtly psychotic. I worked with her fairly intensively for the next three weeks, calming her, but not affecting her psychosis in major ways. During that time, she and her significant other broke up, there was a possibility that she would become homeless, and she had other difficulties. Then her father died suddenly and she was required to 
return to the family home and, seemingly, take over the family business. The psychosis disappeared, she took over the business and both she and it did well. Through no doing of mine, a year later both she and the business were still doing well.

My explanation of the psychosis was that the pain had been, metaphorically, holding her together. She and her body began where the pain began and ended where the pain stopped. I thought that perhaps I had taken that boundary away and triggered the psychotic episode. Faced with the family emergency, she found herself pulled together, perhaps defined by that situation, and in remission again. I have never much liked that explanation and it is probably wrong, but neither have I come up with a better one.

I have written about these cases here because I want to sound a warning. I agree with Hamburg and others like Patterson (2010) that in chronic pain without any medical rationale, the brain may have somehow created an amplifier, so that ordinary sensation becomes amplified into pain. In cases with no indication of serious disorder, the pain might be gradually ameliorated with hypnosis. Or, more in line with the tradition cited by Hamburg, hypnosis may have no effect at all. But there are other cases in which the pain is an important part of the psychic economy, not the equivalent of the remnants of a stitch in one's side. In such cases, there may be nothing specific about hypnosis itself that makes it dangerous. But the history of and common beliefs about hypnosis may make hypnotic suggestion seem to require obedience, and that idea may have untoward results. So, one should thoroughly evaluate medically unexplained pain cases, screen out cases in which extreme reactions seem possible, and proceed cautiously.

\section{MARGIE AND METAPHORS}

As I said above, Hamburg picked out metaphor as the active ingredient in the mix along with the nonspecific factors. I picked out verstehen, active understanding of the patient's phenomenal world and of the points of view of others and the society around her. However, the ways successful therapists explain their success have often confused students and led in unprofitable directions (cf. Ellenberger, 1970). Such explanations have often involved post-hoc narratives based on one personality theory or another, from stimulus-response models to Jung's archetypes. Going to a credentialed psychotherapist has traditionally meant having a conversation with someone who is well acquainted with at least one personality theory. Interventions have been prescribed or proscribed in light of these theories. That is one way that psychotherapy differs from conversations with a sympathetic bartender or hairdresser.

Unsurprisingly in this age of the Dodo-bird (Wampold \& Imel, 2015) and "empirically supported therapies," these theories have come under post-modern scrutiny and are increasingly seen as autobiography rather than an explanation of how people in general function (Atwood \& Stolorow, 2001). As it was triggered by my thoughts about verstehen and metaphor, let me go on a (hopefully brief) tangent about such theories in the spirit of Atwood and Stolorow, who document in detail how the theories of "Sigmund Freud, Carl Jung, Wilhelm Reich, and Otto Rank universalize their creators' personal solutions to nuclear crises and dilemmas of their own life histories” (back cover). 
Leaving Freud alone as an overused trope, let me start with Carl Jung and Alfred Adler. Jung pretended to be an objective student of religious experience (Jung, 1951) continually discovering its mystical basis. His autobiography tells us he was a mystic, possessing from childhood and throughout his life the sense of a direct, experiential relationship to God and of a timeless, eternal self (Jung \& Jaffe, 1962). Adler, a child with rickets, later discovered the universal need to overcome a sense of inferiority based on childhood physical comparisons (Atwood \& Stolorow, 2001).

Let's look at a few others. Wilhelm Reich viewed sexual repression as the root of all evil. At 14, he told his father of his mother's affair with his tutor, and his father beat Reich's mother repeatedly during the following year. Finally, she succeeded at committing suicide (Reich, 2013).

Carl Rogers grew up in a warm household bounded in ideals and behavior by fundamentalist religious beliefs (Elliott \& Farber , 2010). In reaction against the rigidness of these fundamentalist beliefs, but in line with their ideals, he came to value humanistic genuineness and warmth and positive regard without conditions.

Erik Erikson was the child of an unmarried, well-to-do Jewish girl and a passing Dane. She left her home, moved to Germany and eventually married a Jewish doctor. In late adolescence Erikson wandered around Europe, then came to America, married, became a Protestant, and changed his name at birth, "Erik Salomonsen," to "Erik Erikson” (his own son). He later made clear the importance of struggling for and finding a stable social identity in late adolescence (Friedman, 1999).

Then there is Walter Mischel, whose family escaped the Nazis and came to New York. His father, a successful businessman in Austria, could not cope with New York. He became a stay-at-home-father while Mischel's mother became the breadwinner and head of the family. In 1968, Mischel challenged personality psychologists with the notion that measuring traits was almost entirely useless, as people behaved very differently in different situations (Mischel, 2007).

Ending this illustration, there is Albert Bandura, whose parents literally carved out a farm by hand in rural northern Alberta, Canada. Bandura worked his way through the University of British Columbia in three years. Because as a Canadian citizen he was not eligible for available United States grant support, he then worked odd jobs to pay his own way through Kenneth Spence's rigorous doctoral program at Iowa, completing it in another three years. During his seventh year out of the rural high school, he did a clinical internship, then joined the Stanford faculty. He has been there ever since (Bandura, 2007). His self-efficacy theory essentially implies that you can do practically anything you believe you can do. In fact, that is what he did (https://www.psych.ualberta.ca/GCPWS/Bandura/Biography/Bandura_bio1.html ).

It is important to note that one common element among the theorists is that they all became relatively well to do white males who were professors and/or doctors. Few people in the history of the world have had fewer constraints on what they could say and do. It is then unsurprising that they would see people as capable of making decisions based on their unique 
personalities, rather than behaving and stating ideas ascribed to them by means of their gender, social status, and survival needs.

\section{A METAPHOR}

If professionals from Jung to Bandura to Hamburg and I differ widely in their plausible success narratives, what really brings change to our patients? We are forced back to what we all know and agree on: the social context of psychotherapy as a healing ritual. For good or ill, psychology has agreed that psychotherapy is a branch of the healing arts. In this regard, as has often been noted, one of the many problems with medicalizing psychotherapy is that the disease model locates disorder inside the patients. There are no DSM categories for marital discord or familial neglect, never mind poverty, being seen as a wimp by peers, and/or possessing limited models and resources.

We are trained and train students to believe that what we do and what we say to patients (e.g., use metaphor or manifest verstehen) are terribly important. The fact that our office decor, the credentials on the wall , and a caring, but professional demeanor do the heavy lifting is neither appealing nor intuitively obvious. In fact, it is so antithetical to what we think we are doing to affect change that we cannot easily see its products as they appear before our eyes. So please allow me to go over what Hamburg and I and others have come to fully agree on: the basics of the contextual view (e.g., Wampold and Imel, 2015).

Let me use a metaphor. Imagine, if you will, that your plane has crash landed somewhere in the Australian Outback. You are the only survivor. Uninjured, you walk away, alone, from the plane which, as usual in action/adventure stories, then blows up. Thirty or so hours later, getting pretty thirsty and fatigued, you sit down for a rest. You are not certain you will ever get up. Then you notice something: you see a little cabin with a sign that says: "Licensed GuideAustralian Outback.” Filled with hope and renewed interest in what the future will bring, you walk over, knock, and are greeted by the guide.

What happens next is pretty much up to the guide and what you are willing to view as acceptable guidance. ${ }^{1}$ A classic behavioral guide might listen to your story, then equip you with a couple of desert survival skills (like teaching you how to relax and breathe properly in the dry and dusty air).

A client-centered guide might listen to your story and then engage you in a dialogue as follows: Guide (calmly and with sincere interest): "You said that you were looking out the window when the plane went down. Can you remember what you were looking at?" You: "Well, it was confusing. Now that I'm slowing down, I remember seeing some mountains.” Guide:

\footnotetext{
${ }^{1}$ Please forgive the vastly oversimplified depictions and my omission of hundreds of "schools" of psychotherapy (e.g., ACT). It seems obvious to me that when there are 10+ theories and 40+ cures for a disorder like generalized anxiety disorder (NolenHoeksema \& Marroquin, 2017), no one has the whole answer.
} 
"You saw mountains?" You: "Yes, there they are over there. And I remember seeing a town. It would have been over there. No, wait a minute. It was over there.” Guide: “Mmm-hmm.”

A classic humanistic guide (trained in Gestalt) might listen to (some of) your story, then ask: "Have you had a chance to look at the stars at night out here?" You: "No, of course not, I've been too busy, tired and frightened. Don't you understand anything about trauma?” Guide: “It's gotten quite dark. See what happens if you look up for a minute.” You: "Oh my God. The sky is incredible. I've never seen anything like it." Guide: "I'm not clear why you are in such a hurry to get back to the city. Didn't you say that you took that plane because you were pretty bored?”

Finally, a psychoanalytically oriented guide might listen to your story and then inquire: "So, you and your friend boarded the plane despite seeing that one wing was hanging by a thread. Then you said that reminded you of other occasions, some when you were a child. Could you tell me a little more about that?”

Obviously, I could go on. My point is that the feelings and thoughts that mattered most involved finding the guide in the first place. The experience of the "therapeutic honeymoon" suggests that the beginning of therapy can engender a positive relationship. You can miss the potential inherent in the beginning of treatment by ignoring it, by being boorishly incompetent, or by pointing it out and insisting that the effects it induces are ephemeral (Orne and Wender, 1968). The honeymoon can result in early success, success before you get to the supposed heart of treatment (e.g., cognitive restructuring, Longmore \& Worrell, 2007). That can be embarrassing.

\section{THE UBIQUITY OF NONSPECIFIC EFFECTS: THE HISTORY OF MEDICINE AND PSYCHOTHERAPY IS THE HISTORY OF THE PLACEBO EFFECT}

We are so oriented to what we were trained to do that we continue to miss the power of context. We are far from alone in this regard. Prior to Virchow's 1858 publication of Cellular Pathology, the idea of cellular pathology as the basis of disease was very far from the mainstream. Thus, before 1860 or so, much of what doctors did was still based on the work of the Hellenistic era Greek physician philosophers Hippocrates (c. 460 - c. 370 BC) and Galen (AD 129 - c. 200/c. 216) and their followers. Nevertheless, physicians were honored in their societies, whether western or eastern, northern or southern, and no matter whether they wore frock coats, feathers, or togas.

What was it that doctors (using the term generically, so that it includes us) did to earn high status in their societies? First, they named disorders, thus putting one's illness within the realm of the known. Next, different symptom presentations led to a specific prognosis and a specific treatment. The combination provided both the patient and those who knew him with a consistent view of the future. Moreover, patients and those around them knew what to expect and could accept it and/or endure it. 
As far as treatment went, there were a series of tasks related to the illness for the patient, the physician, and other members of the community (Frank, 1973). The physician formulated some ritual or another, recognized by her culture as being the correct treatment for the illness. Note that the fact that whatever nostrum and/or healing ritual was used, it reflected no more knowledge of the complexities of the body than we have now of the brain. And, with very few exceptions until antibiotics came along in the 1940s and 1950s, the nostrums of physicians in all cultures were more likely to do more harm than good. Nonetheless, interaction with physicians and participation in the often (physically harmful) healing ritual was part of what was endured in the social role of being ill (Fish, 1973).

\section{THE PLACEBO IS NOT THE SUGAR PILL, AND THE LONG-LIVED DODO BIRD}

It is only starting somewhere around 1930, when my parents were children, that ordinary physicians began to be generally trained in something looking like modern medicine (Flexner, 1910).

Why do we do bring ourselves and our children to culturally credentialed healers? One goes to an internist or a credentialed psychotherapist expecting that going to the "doctor" should lead to less suffering. That outcome expectancy is part of the placebo effect (Kirsch, 2010). It determines much of what we think and feel, consciously and unconsciously, about our illness and recovery. So, when we respond to a placebo, we are not being tricked by a sugar pill. We are investing our time, money, and energy in the best bet for health that we can make.

In this context it should be noted that in a randomized control trial (RCT), if either a staff member and/or a patient learns s/he is in the placebo condition, it can be embarrassing to get better, both for the staff member and for the patient. The mixed motivation of the staff and such patients may be quite important in studies presented as "placebo controlled" where the blind is, in fact, broken almost immediately. RCTs involving psychiatric drugs and psychotherapies may be particularly sensitive to such knowledge (Kirsch, 2010).

Is it all nonspecific effects? That would be an uncomfortable finding for those interested in mechanisms of change. Is psychotherapy a largely beneficent factor independent of the personality theory (or lack of same) and techniques of individual practitioners (Luborsky, Singer \& Luborsky, 1975; Wampold and Imel, 2015)? Despite ongoing protests, Woolfolk (2015) persuasively argues that this finding or something similar is essentially irrefutable at this stage. Moreover, the gold standard of the RCT design involving a randomized placebo control group is often fool's gold, whether applied to antidepressant medication (Kirsch, 2010) or manualized psychotherapy (Wampold \& Imel, 2015). The professional regard and/or money at stake in outcome research makes allegiance to whichever treatment is preferred by the investigator a constant problem. (Note that allegiance controls may try to exclude relevant biases [Wilson, Wilfley, Agras, \& Bryson, 2011], but such studies are few, far between, and expensive. Further, given the new NIMH priorities and lack of major progress in areas such as depression [Insel, 2012], funding for such research seems unlikely to be abundant in the future.) 
In psychotherapy trials, where double blinding is impossible, most groups who receive inactive treatments are given treatment that has a less convincing rationale, less structure, and is administered less enthusiastically than the theoretically active treatment. For people like me and Hamburg who still believe in the effectiveness of extinction/relearning-based therapies (Craske, 2017) and of hypnosis, that is dismaying.

As I say to my students, if you do something and nothing changes, you know that your intervention did not work. If you do something and things change as you and the patient wish, you can't be certain of what just happened. I think that there is good therapy and that there are good therapists. Moreover, I am tempted to believe that I can recognize both. But I have been both certain and wrong before.

\section{REFERENCES}

Atwood, G. \& Stolorow, R. (2001). Faces in a cloud: Intersubjectivity in personality theory. Lanham, MD: Jason Aronson.

Bandura, A. (2007). Albert Bandura in L. Gardner \& W. Runyan, (Eds). A history of psychology in autobiography Vol. IX. 43-75. Washington, DC: American Psychological Association

Barber, J. (1996). Hypnosis and suggestion in the treatment of pain: A clinical guide. New York: Norton

Craske, M. (2017). Cognitive-behavioral therapy. In J. Carlson and M. Englar-Carlson (Series Eds.) Theories of Psychotherapy. Washington, DC: American Psychological Association

Ellenberger, H. (1970). The discovery of the unconscious: The history and evolution of dynamic psychiatry. New York: Basic Books.

Elliott, R, \& Farber, B. (2010). Carl Rogers: Idealistic pragmatist and psychotherapy research pioneer. In L.Castonguay et al. (Eds.). Bringing psychotherapy research to life: Understanding change through the work of leading clinical researchers. Washington, D.C: American Psychological Association.

Evans, F. (1974). The power of a sugar pill. Psychology Today 7. 55-59.

Fish, J. (1973). Placebo therapy. W. Henry \& N. Sanford (Special Advisors). The Jossey-Bass behavioral science series. San Francisco: Jossey-Bass.

Flexner, A., (1910), Medical education in the United States and Canada: A Report to the Carnegie Foundation for the Advancement of Teaching, Bulletin, 4. New York: The Carnegie Foundation for the Advancement of Teaching.

Frank, J. (1973). Persuasion and healing, $2^{\text {nd }}$ Ed. Baltimore, MD: Johns Hopkins University Press.

Friedman, L. (1999). Identity's architect: A biography of Erik H. Erikson. New York: Scribner.

Gardner-Nix, J. (2013). The mindfulness solution to pain: Step-by-step techniques for chronic pain management. New York: Random House.

Hamburg, S.R. (2018). Metaphoric tasks in psychotherapy: Case studies of “Margie’s” selfimage and “Amy's” pain. Pragmatic Case Studies in Psychotherapy, 13(4), Article 1, 284-328. Available: http://pcsp.libraries.rutgers.edu

Insel, T. (2012). Next-generation treatments for mental disorder. Science Translational Medicine, 4, 1-9. 
Jung, C. (1951). Aion: Researches into the phenomenology of the self. In G. Adler \& R. Hull (Eds.) Collected Works. Vol. 9, Part 2. Princeton, N.J.: Bollingen.

Jung, C. \& Jaffe A. (1962). Memories, dreams, reflections. London: Collins.

Kabat-Zinn, J. (2013) Full catastrophe living (revised edition): Using the wisdom of your body and mind to face stress, pain, and illness. New York: Bantam Books.

Karlin, R. (2005). Maximizing the utility of hypnosis in psychotherapy with the moderately hypnotizable patient. Workshop presented at the 56th Annual Meeting of the Society for Clinical and Experimental Hypnosis, Charleston, SC.

Kirsch, I. (2010). The emperor's new drugs: Exploding the antidepressant myth.

New York: Basic Books.

Longmore, R. \& Worrell, M. (2007). Do we need to challenge thoughts in cognitive behavior therapy. Clinical Psychology Review, 27, 173-187.

Luborsky, I., Singer, B., \& Luborsky, L. (1975). Comparative studies of psychotherapies: Is it true that "everyone has won and all must have prizes"? Archives of General Psychiatry, 32, 995-1008.

Lazarus, A. (1971). Behavior therapy and beyond. New York: McGraw-Hill.

Mischel, W. (2007). Walter Mischel in L. Gardner \& W. Runyan, (Eds). A history of psychology in autobiography, Vol. IX, 227-269. Washington, DC: American Psychological Association

Nolen-Hoeksema, S. \& Marroquin, B. (2017). Abnormal psychology, 7th ed. New York: McGraw-Hill Education.

Orne, M. \& Wender, P. (1968). Anticipatory socialization for psychotherapy: Method and rationale. American Journal of Psychiatry, 124, 1202-1212.

Patterson, D. (2010). Clinical hypnosis for pain control. Washington, DC: American Psychological Association.

Reich, W. (2013). Passion of youth: An autobiography, 1897-1922. New York: Macmillan.

Virchow, R. Die Cellularpathologie in ihrer Begründung auf physiologische und pathologische Gewebelehre. 1858; English translation, 1860.

Wampold, B. \& Imel, Z. (2015). The great psychotherapy debate, $2^{\text {nd }}$ ed.: The evidence for what makes psychotherapy work. New York: Routledge.

Wilson, G. T., Wilfley, D., Agras, W. S. \& Bryson, S. (2011). Allegiance bias and therapist effects: Results of a randomized controlled trial of binge eating disorder. Clinical Psychology: Science and Practice, 18, 119-125.

Woolfolk, R. (2015). The value of psychotherapy: The talking cure in an age of clinical science. New York: Guilford. 